\title{
Morphological description and functions of feathers to support Otus angelinae activities
}

Tyas Rini Saraswati • Enny Yusuf Wachidah Yuniwarti - Silvana Tana

TR Saraswati (Corresponding author) - EYW Yuniwarti - S

email: tyasrinis63@gmail.com

Tana

Department of Biology, Faculty of Science and Mathematics,

Universitas Diponegoro Semarang, Indonesia.

Received: February 18, 2018 • Revised: September 22, 2018 • Accepted: September 26, 2018

\begin{abstract}
Otus angelinae is an owl that known for their silent flight, capable of flying just inches from their prey without being detected. The quietness of their flight is owed to their special feathers. This study aimed to describe the morphology and function of feathers of Otus angelinae. Two Otus angelinae aged 4 months taken from the wild forest of East Java. Owl were sedated with chloroform, dissected, and then observed to know the morphological of feathers that coat its body. The results showed that each part of the body of an owl composed of different morphology and size of feathers to support the activity of flying.
\end{abstract}

Keywords: owl, silent flight, wild animal

\section{Introduction}

Feathers serve several important functions. The primary functions of feathers on owl are to provide protection, insulation, and capacity for flight. Insulation is essential to regulate the body temperature. In addition to the functions, the color of feathers also has an important role, which is for camouflage to avoid predator in nature (Stevens et al 2014). Owls are known for their silent flight (Rodriguez et al 2009). Several specializations of the feathers have been implicated in the noise reduction (Bachmann et al 2012). This noise reduction is caused by the morphology of feathers that arranged on its body. Otus angelinae have brown feathers striated with black and white spots. It has a short tail but very wide wings. Flapping wings are hardly make sound when it is flying, making their preys unaware of its existence. Most owls have relatively large wings. The wings were broad, with a large surface area compared to the body weight. This allows them to fly lightly and easily without extensive flapping that leads to loss of energy. They can slide easily and fly slowly for long periods. When threatened, the owl will take a hidden position, i.e., closed eyes, lifted ear tufts, and compacted fur.

Otus angelinae is a nocturnal, which means they are very active at night. In search of prey, they rely on their senses of sight and very sharp hearing (Orlowski et al 2012). The feathers on the face helps to direct sound so it can detect the presence of prey simply by using voice (Ibbara et al 2014). Their eyes are facing forward with big eyeballs that always bulging and the head can rotate up to 270 degrees. Based on these reason it is necessary to do research about the identification of feathers morphology of Otus angelinae.

\section{Materials and Methods}

This research is a descriptive research. Two Otus angelinae females aged 4 months were taken from the wild forest of East Java region. Otus angelinae body were weighed, anesthetized with chloroform, and observed. The observation of morphology, weight and length of the feathers were carried out through various areas of the body. The description and analysis of feather morphology were done related to its functions.

\section{Results and Discussion}

\section{Feathers covering the body}

Measurements of body weight and feathers are shown in Table 1. The results showed that the feathers covered until $25 \%$ of the total body weight of Otus angelinae. The feathers are spread all over the body with a morphology, which are different for each part as shown in the Figure 1.

Table 1 Results of the measurement of body weight, the weight of feathers on chest, head, tail, wing, and body of Otus angelinae.

\begin{tabular}{llc}
$\mathrm{N}^{\mathrm{o}}$ & Parameter & Weight \\
\hline 1 & The body weight $(\mathrm{g})$ & 57.71 \\
2 & The chest feathers weight $(\mathrm{g})$ & 1.65 \\
3 & The head feathers weight $(\mathrm{g})$ & 0.26 \\
4 & The tail feathers weight $(\mathrm{g})$ & 2.2 \\
5 & The wing feathers weight $(\mathrm{g})$ & 8 \\
6 & The body feathers weight $(\mathrm{g})$ & 2.28 \\
\hline
\end{tabular}




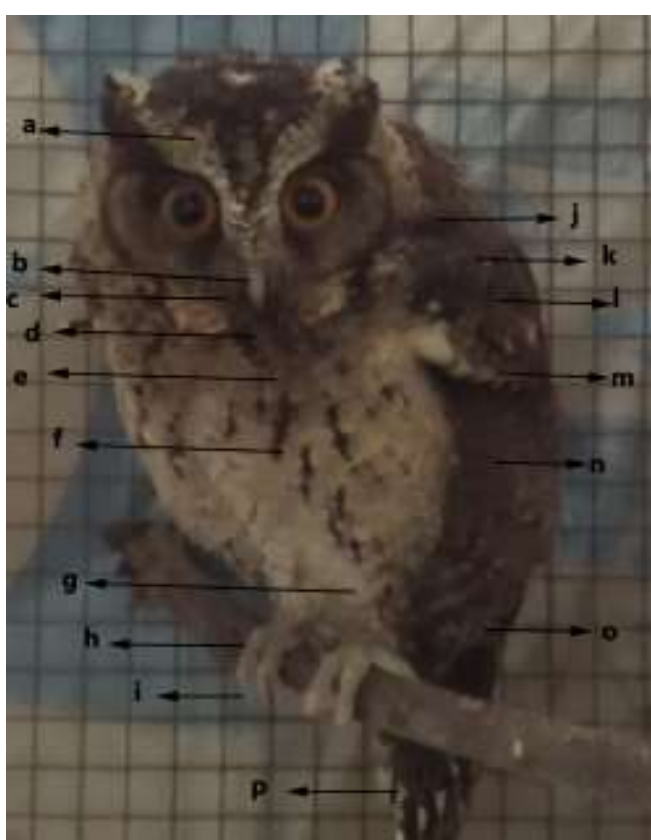

Figure 1 Morphology and body part of Otus angelinae.

a. Eyebrow or supercilium, b.Bill, c. Chin, d. Throat, e. Breast, f. Belly, g. Flanks, h.Toe, i. Claw, j. Collar, k. Back, 1. Scapular, m. Lesser coverts, n. Secondary coverts, o. Primaries, p. Tail.

Otus angelinae have up to five feather types: Contour feathers which cover the body and constitute the flight feathers of the wing (remiges) and tail (rectrices); Down feathers which has soft and fluffy, trap air and create a layer of insulations next to the its body; Semiplumes which commonly found under contour feathers, especially on the sides of abdomen and along the neck and back. Semiplumes feathers provide insulation; Bristle or small feathers which most commonly found around the base of the bill, eyes, and as eyelashes; Filoplumes which has a hair like structure. They are typically covered by other feathers, and may function as pressure and vibration receptor (Colville and Bassert 2008).

\section{Facial Feathers}

Some feathers around the face of Otus angelinae are specially designed, i.e., the stiff facial disc feathers, ear-tuft, ear-flap feathers and also bristles around the bill. Otus angelinae have their face feathers arranged like two dishes (facial discs) to collect and channel sounds into their ears so they can more accurately locate prey in the dark. Otus angelinae use their facial disc to adjust their hearing, allowing more sound to come into one ear than the other does just by moving the feathers around its face (Berge 2005).

The ear-tufts feathers are not the owl's ears but rather clumps of feathers found on heads. They are used to indicate mood, such a fear, anger, and excitement. They also help with camouflage (Perrone 1981). Ear tufts help owl to distinguish to make owl look fiercer to predators and help owls to communicate (Santillan et al 2008).

Bristles are specialized feathers that are believed to perform a tactile function. Otus angelinae bristles at approximately $1.4 \mathrm{~cm}$. These feathers is stiff and tapered. Bristles are found on the head, around the mouth or eyelids. Bristles in Otus angelinae, are thought to aid the bird in sensing nearby objects. The bristles indicate that this bird may not see well and uses the bristles to explore objects in front of his beak

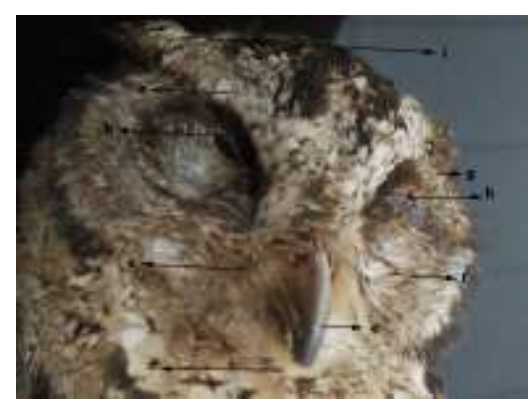

A

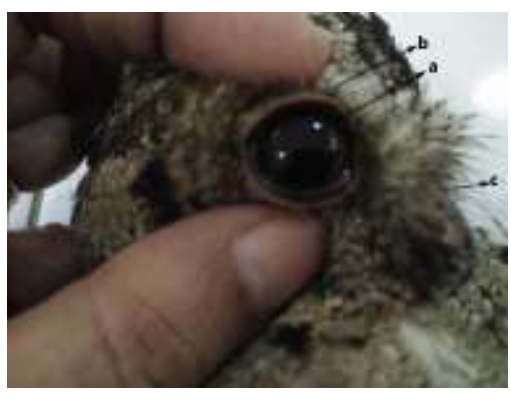

B

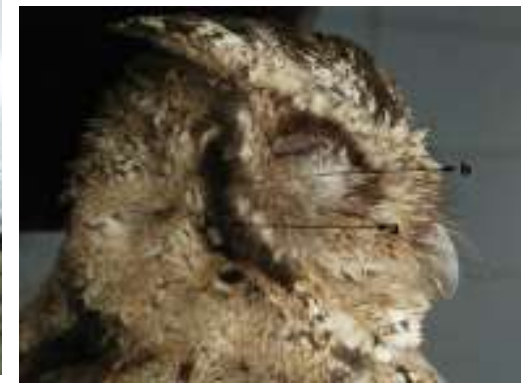

C

Figure 2 A. Facial of Otus angelinae. a. Eyebrows, b. Eyelid, c. Bristles, d. Chin, e. Bill, f. Facial disc,g. Rim, h. Nictitating membrane, i. Ear-tuft; B. the eye exposed and the membrane open; C. Nictating membran covered the eyes of Otus angelinae.

Nictitating membrane is a thin, white colored layer that can be used to lubricate and protect the eye. Figure 2B shows the image when owl's eye are exposed and opened, while in figure $2 \mathrm{C}$ shows the eye covered by the nictating membrane.

The feathers on the face covering the eyes, nose, ears. Otus angelinae have very large eyes. The results showed that the weight of Otus angelinae eyes are $20 \%$ of the total weight of the head. Otus angelinae's eyes are so large, they fill most of the cranial cavity, with eyes that always face to the front, and they have to turn the entire head to get side objects in view. Eye size is very important for seeing at night. Because an owl's eyes are so large, they have a large surface area to collect light. 
The results showed that the diameter of the ear of Otus angelinae is $0.9 \mathrm{~cm}$ (Figure 3). Because Otus angelinae are generally active at night, they have a highly developed auditory (hearing) system. The ears are located at the sides of the head, behind the eyes, and are covered by the feathers of the facial disc.

The feathers on the face of an owl that captures sound waves and pass into the ear. The feathers are also separate one from the other ear so the sound coming from the right direction will be more clearly heard by the right ear. Otus angelinae have asymmetric ears, one ear is higher than the other. The higher ear often facing upwards, while the lower face down. It can detect the exact location of the sound thus Otus angelinae are able to determine the direction the sound that coming from all directions although he did not see his prey. A flexible layer composed of short hairs (Figure 2A) like feathers that covered her facial disc covers ear holes. The layer serves as a sound reflector. Those various hearing features make Otus angelinae have a very sensitive hearing to the sound thus they are able to detect the location of prey (in the direction and distance) exactly even in the dark. The middle ear sends vibrations from the tympanic membrane to the inner ear and in the middle area; there is a cochlea with imperfect spiral-shape.

\section{Wing Feathers}

The length of the stretched wings is $15 \mathrm{~cm}$, with a width of up to $10 \mathrm{~cm}$. Flight feathers of the wing are collectively known as the remiges, and are separated into primary and secondary. The primaries are attached to the metacarpal (wrist) and phalangeal (finger) bones at the far end of the wing and responsible for forward thrust. There are 10 primaries and they are numbered from the inside out. The secondary are attached to the ulna, a bone in the middle of the wing, and are necessary to supply "lift". There are 12 secondary and they are numbered from the outside in.

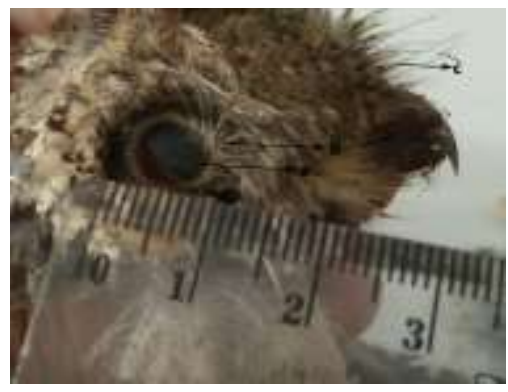

Figure 3 Otus angelinae's ears.
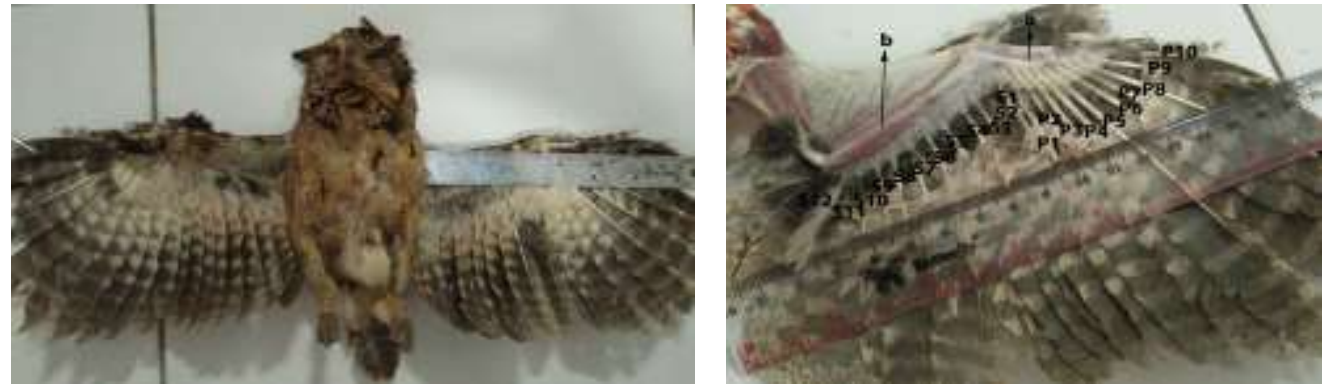

Figure 4 Wing Feathers. a. Lesser covert, b. Secondary covert, c. Tertials, d. Bend of wing, e. Alula, f. Primary covert, g. Tail feathers or rectrices. P10-S10: Remiges, P1-P10: Primary, S1-S10: Secondary.

The primary wing feathers have a comb like structure (Figure 6). In normal flight conditions, the air will approach the wing surface, creating turbulence, and make noise. Feather wings with the tip of the comb-shaped model will make the turbulence of air waves becomes micro turbulent. It is effective to dampen the sound in the upper surface of the wing and allows birds to fly silently. Other fine hairs covering the surface of the wing are used to reduce the noise.
The bases of the flight feathers are covered with smaller contour feathers called coverts. There are several layers of coverts on the wing. Down feathers are small, soft, fluffy, and are found under the contour feathers. They are called as plumaceous. This makes it possible for the bird to trap air in an insulating layer next to the skin, and protect the bird from heat and cold. The length and the width of the wingspan, the length of the wing feathers and tail feathers are showed in Table 2. 
Table 2 The length of the wingspan, the width of the wingspan, the length of the wing feathers and tail feathers.

\begin{tabular}{lc}
\hline Parameter & Size \\
\hline Length of the wingspan $(\mathrm{cm})$ & 15 \\
Width of the wingspan $(\mathrm{cm})$ & 12 \\
Length of the wing feathers $(\mathrm{cm})$ & 10 \\
Length of the tail feathers $(\mathrm{cm}$ & 6.8 \\
\hline
\end{tabular}

Feathers on the backside of the wings have tufts which are able to disperse sound waves that arise when the wind flow over the wing when they flapped their wings down. The down feathers in other parts of his body helped muffle the remaining sound.

\section{Tail Feathers}

The tail feathers, called retrices, act as a brake and rudder, controlling the orientation of the flight. Otus angelinae have 10 tail feathers. The tail feathers length is approximately $6.8 \mathrm{~cm}$. When the owl is flying, its tail feathers help it to direct itself. There is a small gland called uropygial, which is located at the base of the tail, with a length of $1.1 \mathrm{~cm}$. Uropygial gland produces oil to lubricate the feathers and beak and also to make them waterproof. The owl spreads this oil all over the feathers and body.

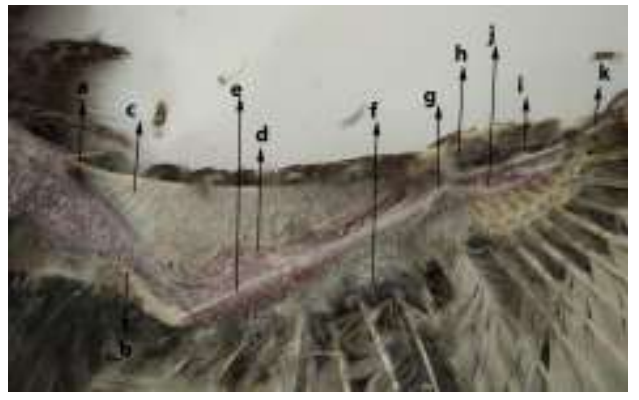

A

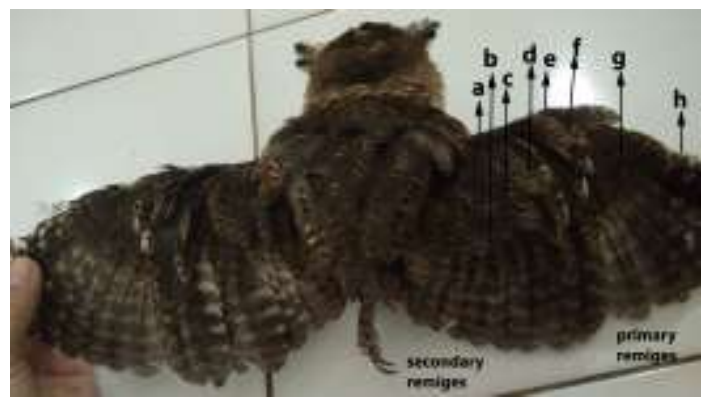

B

Figure 5 A. View Ventral.a. Patagialis longus tendon, b. Humerus, c. Patagium, d.Radius, e. Ulna, f. Postpatagium, g. Radiale and ulnare, h. First digiti, i. second digiti,j. Carpometacarpus, k. Rachis of $10^{\text {th }}$ primary remix. B. View Dorsal. a. Marginal covert, b. Greater secondary covert, c. Median secondary covert, d. Lesser secondary covert,e. Alular Covert, f.Alula, g.Greater primary covert, h. $10^{\text {th }}$ primary remix.

Leg has Filoplumes that works much like an antenna; to help owls react to things they touch e.g. their prey. Otus angelinae use their beak and claws to clean the bristles and remove dust, dirt and parasites. Two outer claws on the foot are useful as a "comb feather". Sharp medial end of the outer claws allow them to clear the head.

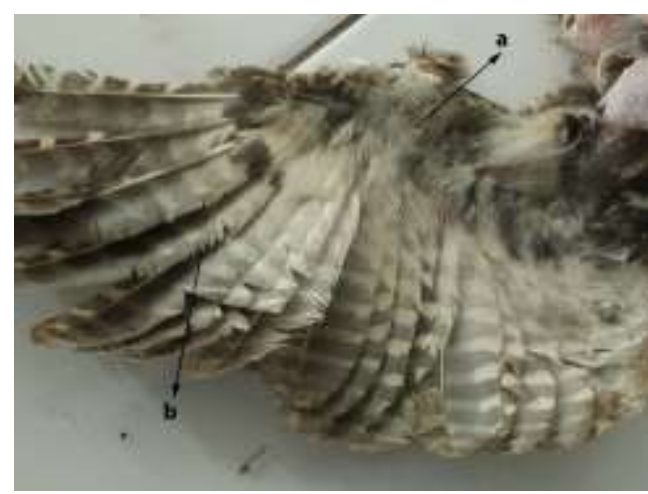

Figure 6 Wing feathers.

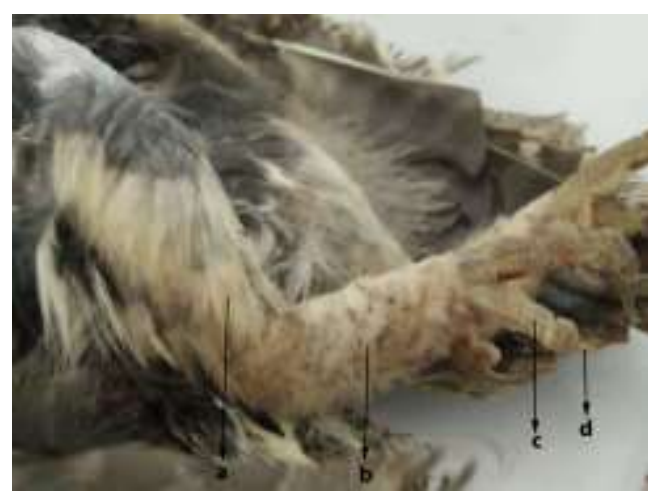

Figure 7 Fee feathers.

\section{Conclusion}

Every part of Otus angelinae body covered by feathers with different morphology to support the activities of fly and prowl. 


\section{Acknowledgment}

This article was part of the results of research funded by Penerimaan Negara Bukan Pajak (PNBP), Riset Penerapan dan Pengembangan (RPP) 2016. Our gratitude goes to the Directorate General of Higher Education and Lembaga Penelitian dan Pengabdian kepada Masyarakat (LPPM)Universitas Diponegoro.

\section{References}

Bachmann T, Wagner H, Tropea C (2012) Inner vane fringes of barn owl feathers reconsidered: morphometric data and functional aspects. Journal of Anatomy 221:1-8.

Berge S (2005) Owls. Published by Stackpole Books. 5067 Ritter Road, Mecanicsburg, Pennsylvania, 15-30.

Colville T, Bassert JM (2008) Clinical anatomy and physiology for veterinary technician third edition, 3rd Ed, Elsevier: Amsterdan.

Ibbara JT, Martin K, Altamirano TA, Vargas FH, Bonacic C (2014) Factor associated with the detectability of owls in south american temperate forest: implications for nocturnal raptor monitoring. The journal of wildlife management 78:1078-1086.
Orlowski J, Harmening W, Wagner H (2012) Night vision in barn owls: Visual acuity and contrast sensitivity under dark adaptation. Journal of Vision 12:1-8.

Perrone M (1981). Adaptive significance of ear tufts in owl. Condor 83:383-384.

Rodriguez A, Siverio F, Barone R, Rodriguez B, Negro JJ (2009) An overlooked cost for the velvety plumage of owls. Entanglement in adhesive vegetation. The Wilson Journal of Ornitology 121:439-441.

Sangster G, King, BF, Verbelen, P, Trainor, CR (2013) A new owl species of the genus otus (aves: strigidae) from lombok, indonesia. PLoS ONE 8:e53712.

Santillan MA, Sarasola, JH, Dolsan, M (2008) Ear tufts in ferruginous pygmy-owl (Glaucidium brasilianum) as alarm response. Journal of raptor research 42:153-154.

Stevens M, Lown, AE, Wood, LE (2014) Color change camouflage in juvenile shore crabs Carcinus maenas. Frontiers in Ecology and Evolution. DOI: 10.3389/fevo.2014.00014 